

\title{
Collateral Assessment by CT Angiography as a Predictor of Outcome in Symptomatic Cervical Internal Carotid Artery Occlusion
}

\author{
(D) S. Sundaram, DS. Kannoth, DB. Thomas, DP.S. Sarma, and (DP.N. Sylaja
}

\begin{abstract}
BACKGROUND AND PURPOSE: Cervical internal carotid artery occlusion can present with varied clinical manifestations such as transient ischemic attack, stroke, and chronic ocular ischemia, or can be asymptomatic. The outcome in these patients is considerably influenced by cerebral hemodynamic compensatory adaptation of the intracranial collateral pathways. Our aim was to study whether collateral circulation as assessed by CT angiography can predict 3-month outcome and initial stroke severity in patients with symptomatic cervical ICA occlusion.
\end{abstract}

MATERIALS AND METHODS: This was a retrospective study of 65 patients with symptomatic cervical ICA occlusion from January 2011 to December 2013. The collateral vessels (anterior and posterior communicating arteries, ophthalmic artery, and leptomeningeal arteries) were assessed by CTA. The outcome at 3 months was defined as poor if the modified Rankin Scale score was $\geq 3$.

RESULTS: The mean age of subjects was $57 \pm 11.6$ years (range, 32-80 years), and $92 \%$ were men. Thirty-three (50.8\%) patients had poor outcome. Absence of the ipsilateral ophthalmic artery, poor leptomeningeal collaterals, and $<2$ collaterals were predictors of stroke severity at onset and poor 3-month outcome in univariate analysis. In the multiple logistic regression analysis, inadequate flow through the secondary collaterals (ipsilateral ophthalmic artery or leptomeningeal collaterals; OR, $4.5 ; 95 \% \mathrm{Cl}, 1.4-14.9 ; P=.01$ ) and higher $\mathrm{NIHSS}$ score at stroke onset (OR, 19.2; 95\% Cl, 2.2-166.2; $P=.007)$ independently predicted poor outcome at 3 months.

CONCLUSIONS: Assessment of collateral circulation with CTA can be a useful predictor of 3-month outcome in patients with symptomatic cervical ICA occlusion.

ABBREVIATIONS: $\mathrm{AcomA}=$ anterior communicating artery; $\mathrm{LC}=$ leptomeningeal collaterals; $\mathrm{OA}=$ ophthalmic artery; $\mathrm{PcomA}=$ posterior communicating artery

C ervical ICA occlusion can present with varied clinical manifestations such as transient ischemic attack, stroke, and chronic ocular ischemia, or can be asymptomatic. The outcome in these patients is influenced by cerebral hemodynamic compensatory adaptation, with the intracranial collateral pathways playing an important role in maintaining adequate perfusion to the ischemic zone. ${ }^{1}$

In large-artery occlusion, the primary collaterals (anterior and posterior communicating arteries) act as the immediate flow diverters and the secondary collaterals (leptomeningeal and oph-

Received May 29, 2016; accepted after revision August 14.

From the Department of Neurology (S.S., P.N.S.), Comprehensive Stroke Care Program; Department of Imaging Sciences and Interventional Radiology (S.K., B.T.); and Achutha Menon Centre for Health Science Studies (P.S.S.), Sree Chitra Tirunal Institute for Medical Sciences and Technology, Trivandrum, India.

Please address correspondence to P.N. Sylaja, MD, Department of Neurology, Comprehensive Stroke Care Program, Sree Chitra Tirunal Institute for Medical Sciences and Technology, Trivandrum 695011, Kerala, India; e-mail: sylajapn@hotmail.com

三 Indicates article with supplemental on-line table.

http://dx.doi.org/10.3174/ajnr.A4957 thalmic arteries [OAs]) further enhance the cerebral perfusion. ${ }^{2}$ The role of collaterals as predictors of stroke severity, response to thrombolysis, and outcome in patients with acute stroke and large-vessel occlusion has been investigated in multiple studies. ${ }^{3-5}$ Good leptomeningeal collateral circulation and the presence of $\geq 2$ collaterals were found to be associated with good outcome in patients with cervical large-vessel occlusion. ${ }^{6,7}$

Most of the earlier studies on collaterals have focused on the prognostic implications of primary collateral circulation and cerebrovascular autoregulation in patients with stroke. Only a very few of them have explored the clinical significance of secondary collaterals, especially the ophthalmic artery, in ICA occlusion. The earlier studies were also limited by the nonuniformity of study protocols, especially the imaging technique with a combination of either MRA, DSA, CTA, or transcranial Doppler for assessing the cerebral collaterals. We analyzed both primary and secondary collaterals by using CTA, which is a noninvasive technique currently recommended for the evaluation of vascular anatomy in stroke. The main objective of our study was to determine whether collateral circulation as assessed by CTA helps in predict- 


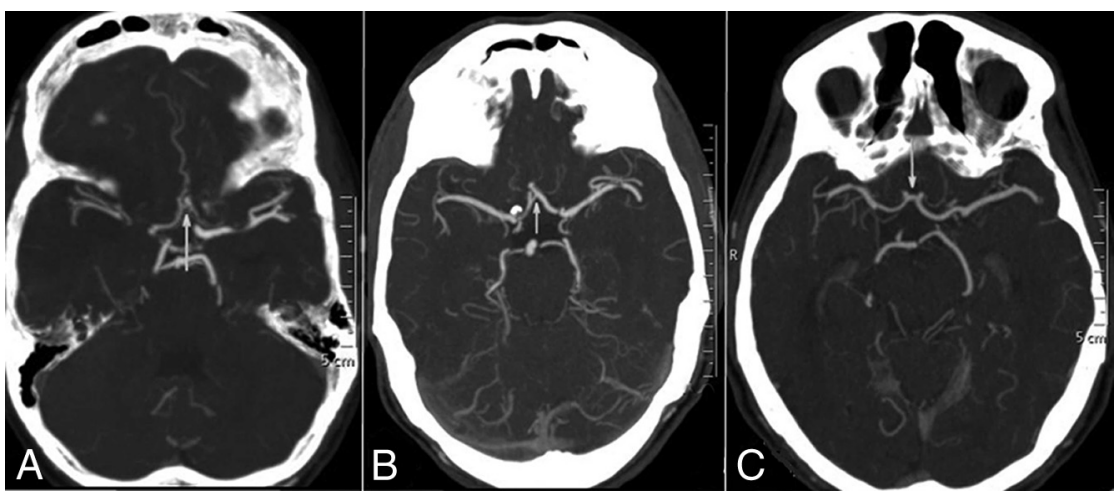

FIG 1. CT angiographic grading of the anterior communicating artery shows a hairline $\operatorname{AcomA}(A)$, definitely present AcomA (B), and robust AcomA (C).

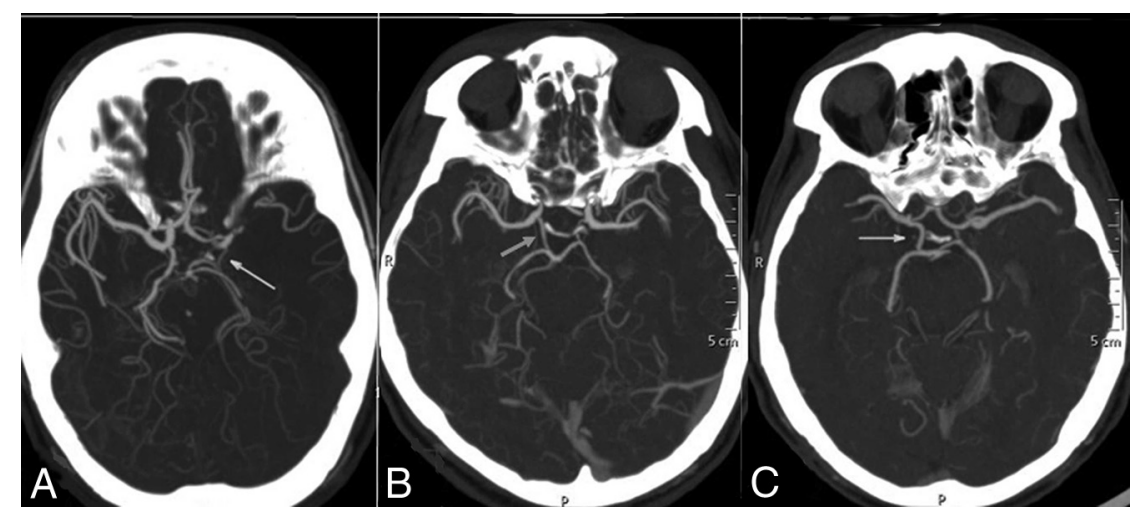

FIG 2. CT angiographic grading of the posterior communicating artery shows a hairline PcomA $(A)$, definitely present PcomA (B), and robust PcomA (C).

ing the 3-month outcome and initial stroke severity in patients with symptomatic cervical ICA occlusion.

\section{MATERIALS AND METHODS \\ Subjects}

This was a retrospective study, conducted in the Comprehensive Stroke Care unit of a tertiary care center. All patients with symptomatic cervical ICA occlusion who presented to the unit from January 2011 to December 2013 satisfying the selection criteria were included in the study. Patients older than 18 years of age who had a TIA (hemispheric/retinal) or stroke with ipsilateral extracranial ICA occlusion who underwent CTA of the cerebral circulation within 3 weeks of symptom onset were included. Those with intracranial ICA occlusion, asymptomatic ICA occlusion, tandem MCA occlusion, and ICA occlusion due to Moyamoya disease and patients who underwent revascularization therapy were excluded. The study had the approval of the institutional ethics committee.

\section{Assessment of Subjects}

The demographic and clinical profiles of patients, including vascular risk factors, were extracted from the patient records. Stroke severity at the initial presentation was expressed by the NIHSS score. CT, MR imaging, and CTA were reviewed independently by an interventional neuroradiologist and stroke neurologist. The 2 CTA readers were blinded to the clinical information and outcome.
The baseline CT scan was used for assessing the ASPECTS, and a score of $\geq 8$ was considered good. The type of infarct was classified into territorial (involving $>1$ subdivision of the MCA), hemodynamic (watershed or borderzone infarcts), or other (small infarcts of $<1 \mathrm{~cm}$ located in the cortex or centrum semiovale or no infarct). ${ }^{8}$

\section{Collateral Assessment by CTA}

CTA is routinely used for the evaluation of all patients with stroke for delineating the vascular anatomy in our center if there is no contraindication. CTA was obtained with $\mathrm{z}$-axis coverage from the arch of the aorta to the vertex. All the imaging studies were acquired in a 256section CT scanner (Brilliance iCT; Philips Healthcare, Best, the Netherlands) with the following technical parameters: section thickness, $0.9 \mathrm{~mm}$ (pitch, 0.6); collimation, $0.625 \mathrm{~mm}$; gantry rotation speed, $-500 \mathrm{~ms} ; 120 \mathrm{kV}$ (peak); 450 mAs; FOV, 200-250 mm; and $512 \times 512$ matrix. Angiography was performed by using bolus tracking by placing a region of threshold (ROI) in the upper descending thoracic aorta, triggering the acquisition beyond the threshold of $150 \mathrm{HU}$. A total of 50-60 $\mathrm{mL}$ of low-osmolar contrast medium (iohexol, $320 \mathrm{mg} / \mathrm{mL}$, or iodixanol, $270 \mathrm{mg} / \mathrm{mL}$ ) was administered through an 18-ga cannula secured in the right antecubital vein at the rate of $5 \mathrm{~mL} / \mathrm{s}$ followed by a saline chase of $40 \mathrm{~mL}$ at $5 \mathrm{~mL} / \mathrm{s}$. The images were later transferred to a dedicated vendor workstation for detailed interpretation. MIP images of 5-mm thickness were created from CTA source imaging for the assessment of the collateral circulation.

The grading system of Maas et $\mathrm{al}^{9}$ was adopted in this study for the flow through the anterior communicating artery (AcomA), posterior communicating artery (PcomA), and the leptomeningeal collaterals (LC). A 5-point grading system was used for the assessment of flow through the AcomA (Fig 1) and the ipsilateral PcomA (Fig 2): Grade 1 denoted absent flow; grade 2, probably present; grade 3, hairline; grade 4, definitely present; and grade 5, robust. LC were graded by comparing the symptomatic hemisphere with opposite side categorized into 5 grades (Fig 3): grade 1, absent; grade 2, less than those on the contralateral side; grade 3, equal to those on the contralateral side; grade 4 , greater than those on the contralateral side; and grade 5 , exuberant. ${ }^{9}$ Because the number of patients in each group was not enough for any statistical analysis to be relevant, the grades were collapsed into 2 grades. LC were dichotomized into poor (grades 1 and 2) and good (grades 3, 4, and 5) collaterals. Similarly, the AcomA and PcomA were dichotomized into poor (grades 1,2, and 3) and good (grades 4 and 5) flow. Grading of the leptomeningeal and com- 


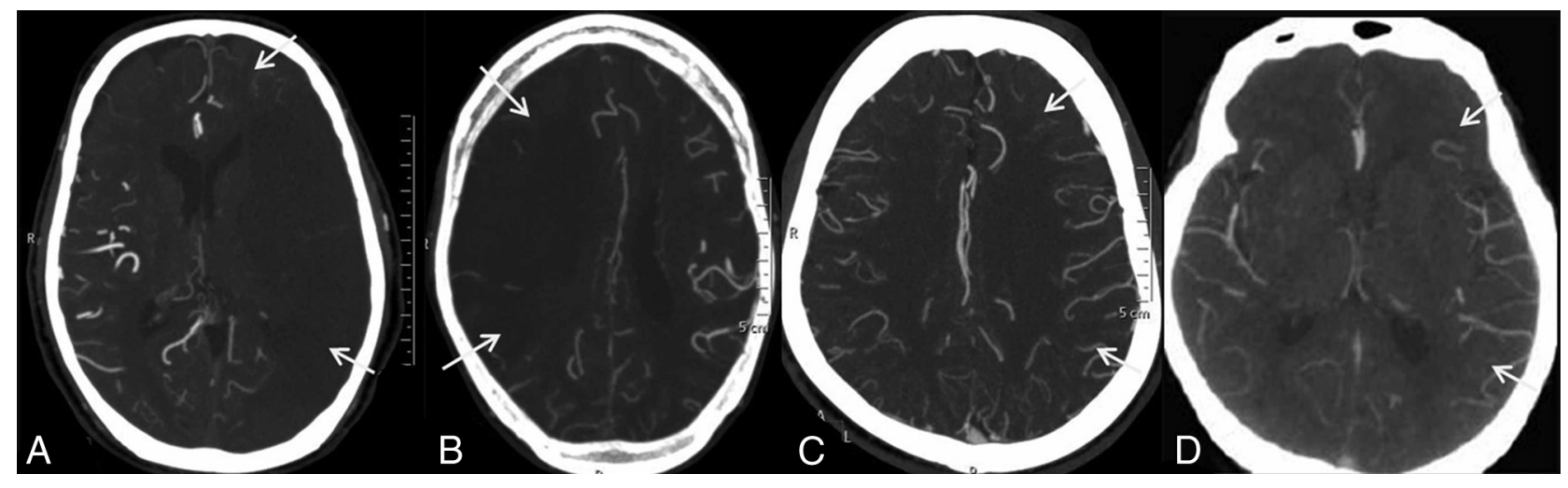

FIG 3. CT angiographic grading of leptomeningeal collaterals compared with the side contralateral to the symptomatic cervical ICA occlusion shows absent leptomeningeal collaterals $(A)$, reduced leptomeningeal collaterals $(B)$, equal leptomeningeal collaterals $(C)$, and leptomeningeal collaterals more than on the opposite side $(D)$.

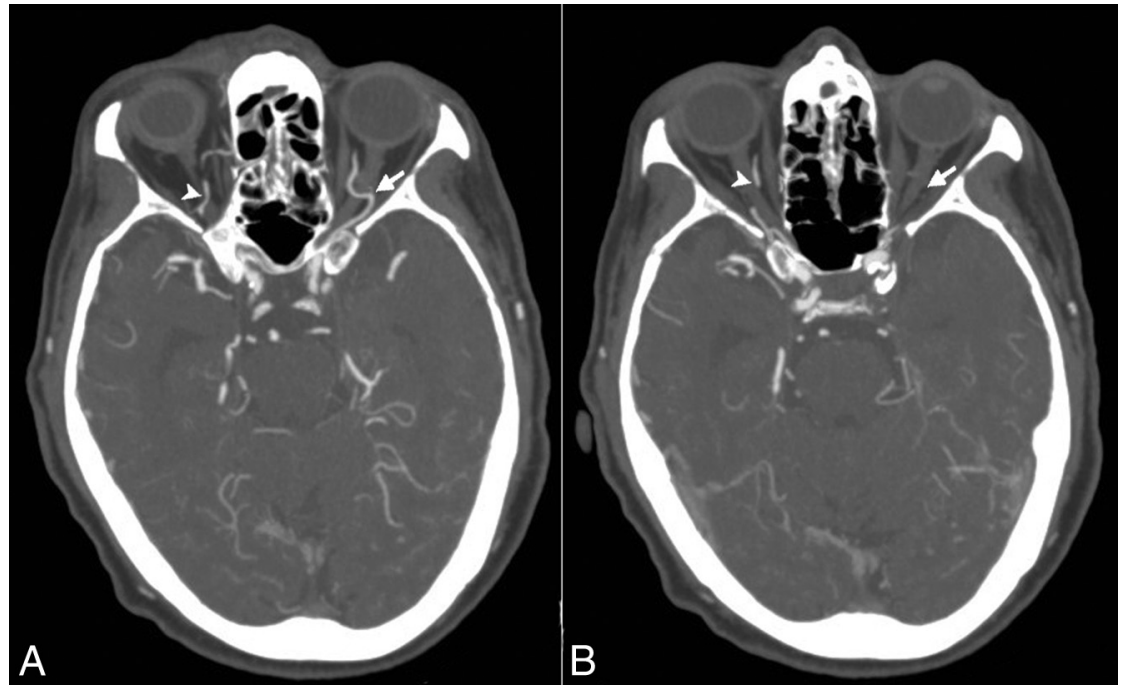

FIG 4. CT angiographic axial images showing the presence $(A)$ and absence $(B)$ of the ophthalmic artery on the side of the symptomatic cervical ICA occlusion (arrow) and the presence of the ophthalmic artery on the opposite side (arrowhead).

municating arteries were not similar. Absent, probably present, and hairline communicating arteries may not contribute significantly to collateral circulation; hence, grades $1-3$ were taken together as the poor-flow group, whereas in LC, either absent or less than those in the opposite hemisphere, constituted poor flow. The OA on the ipsilateral side of the ICA occlusion was graded as present or absent on the basis of its perceptibility on CTA (Fig 4).

\section{Outcome Assessment}

All patients received standard care as per the current stroke guidelines, with the best medical management and control of modifiable vascular risk factors. Patients with large-vessel atherosclerotic disease and dissection received antiplatelet agents and high-dose statins, while the 2 patients with cardioembolic ICA occlusion received anticoagulation. The functional outcome at 3 months was assessed by the $\mathrm{mRS}$, and poor outcome was defined as $\mathrm{mRS} \geq 3$. The mortality and recurrent ischemic events were recorded during follow-up.

\section{Statistical Analysis}

Continuous variables were reported as means or as median \pm interquartile range. Categoric variables were reported as propor- tions. Differences in continuous variables and proportions were assessed by ANOVA and the $\chi^{2} /$ Fisher exact test, respectively. Interobserver agreement for the status of collaterals was assessed with $\kappa$ statistics, and in cases in which there was divergence between the 2 assessors, a consensus decision was reached.

Baseline characteristics (age, sex, vascular risk factors, and prior neurologic events), NIHSS score at stroke onset, type of infarct, ASPECTS, and collaterals were compared between excellent $(\mathrm{mRS} \leq 2)$ and poor ( $m R S \geq 3$ ) outcome groups. On the basis of initial stroke severity, patients were grouped into mild (NIHSS $<5$ ) and moderate-to-severe (NIHSS $\geq 5$ ) stroke. The baseline characteristics and collaterals were also compared between these 2 groups.

Among the predictors of 3-month outcome significant in univariate analysis $(P<.05)$, highly correlated variables were excluded while retaining 1 of them that was clinically relevant for multiple logistic regression analysis. Two models were included for multivariable analysis of 3-month outcome based on the results from univariate analysis. In model 1 of multiple logistic regression analysis, the ipsilateral OA and LC were independently analyzed along with the NIHSS score, and in model 2, both the ipsilateral OA and LC were analyzed together as secondary collaterals along with the NIHSS score for predicting 3-month outcome. Due to small cell values (zero) for a few parameters, multivariable analysis was not attempted for assessing the predictors of stroke severity. The results of multivariable analysis were expressed as ORs with 95\% CI. All statistical analyses were performed by using SPSS 21 software for Windows (IBM, Armonk, New York).

\section{RESULTS}

Sixty-five patients were identified from 73 with symptomatic ICA occlusion. Five patients with intracranial ICA occlusion and 3 with ipsilateral MCA occlusion were excluded. 
The mean age of subjects was $57 \pm 11.6$ years (range, $32-80$ years), with 60 (92\%) men. Sixty-one patients (93.8\%) had stroke, and 4 patients $(6.2 \%)$ had transient ischemic attack as the initial presentation. The median NIHSS score at presentation was 10 (interquartile range, 4-18). Territorial infarcts were seen in 24 (36.9\%), hemodynamic infarcts in 23 (35.4\%), and small cortical or superficial infarcts or no infarct, in $18(27.7 \%)$ patients. Poor ASPECTS was seen in 23 patients (35.38\%). Atherosclerosis was the most common cause of ICA occlusion observed in 43 patients (66.2\%), followed by arterial dissection in 20 (30.8\%) and cardioembolic stroke in 2 (3\%) patients.

The median time interval from the onset of symptoms to the acquisition of CTA was 74.0 hours (range, 2-504 hours). Interobserver agreement for the status of collaterals by using $\kappa$ statistics showed good agreement $(\kappa=0.89)$. Good flow through the AcomA, ipsilateral PcomA, and LC was seen in 34 (52.3\%), 26 (40\%), and 47 patients $(72.3 \%)$, respectively. The ipsilateral OA was not visualized in 26 patients (40\%).

All patients had 3-month follow-up, and 33 patients (50.8\%) had poor outcome. The presence of an MCA territory infarct $(P=$ $.002)$, poor ASPECTS $(P<.001)$, higher NIHSS score at stroke onset $(P<.001)$, absent ipsilateral OA $(P=.02)$, poor flow through the $\operatorname{LC}(P=.001)$, and no or only 1 collateral $(P=.005)$ were significant univariate predictors of poor outcome at 3 months (Table 1). The role of the AcomA and PcomA was not significant in determining outcome. In patients with an absent ipsilateral OA, 18 (69.2\%) had poor outcome, and 15 of the 18 patients $(83.3 \%)$ with poor flow through the LC had poor outcome. Patients with either no or only 1 collateral had poor outcome compared with patients with $\geq 2$ collaterals (76.2\% versus $38.6 \% ; P=.005)$.

In multiple logistic regression analysis of 3-month outcome, highly correlated variables were excluded by retaining one of them that was clinically relevant (Table 2 ). In model 1 , only the NIHSS score was found to be a significant predictor of 3-month outcome (OR, 16.5; 95\% CI, 1.9-142.2; $P=.01$ ). In model 2 of multivariable analysis, absence of either of the secondary collaterals (ipsilateral OA or LC; OR, 4.5; 95\% CI, 1.4-14.9; $P=.01$ ) and higher initial NIHSS score (OR, 19.2; 95\% CI, 2.2-166.2; $P=.007)$ were independent predictors of poor outcome at 3 months.

Patients with large territorial infarcts $(P<.001)$, an ASPECTS of $\leq 7(P<.001)$, an absent ipsilateral OA $(P=.04)$, poor flow through the $\mathrm{LC}(P<.001)$, and $<2$ collaterals $(P=.01)$ were found to have higher NIHSS score at stroke onset (On-line Table). All 18 patients with poor LC had severe stroke. However, multiple logistic regression analysis for stroke severity could not be performed due to the small cell size.

Four patients (6.2\%) died, 3 from malignant MCA stroke and 1 patient from myocardial infarction after discharge. Only 2 patients $(3.1 \%)$ had recurrent vascular events. Age, sex, vascular risk factors, and etiology of the ICA occlusion were not predictive of the 3-month outcome or initial stroke severity.

\section{DISCUSSION}

Our study highlights the role of the secondary collaterals (ie, OA on the side of ICA occlusion and LC) in determining stroke outcome. Poor collateral circulation through either the LC or ipsilat-
Table 1: Demographic data, vascular risk factor profile, clinical parameters, and collateral circulation ${ }^{\mathrm{a}}$

\begin{tabular}{|c|c|c|c|}
\hline $\begin{array}{c}\text { Clinical Imaging } \\
\text { Parameters }\end{array}$ & $\begin{array}{c}\text { Excellent } \\
\text { Outcome } \\
(\mathrm{mRS} \leq 2) \\
(n=32)\end{array}$ & $\begin{array}{c}\text { Poor } \\
\text { Outcome } \\
(\mathrm{mRS} \geq 3) \\
(n=33)\end{array}$ & $\begin{array}{c}P \\
\text { Value }\end{array}$ \\
\hline Age (yr) (mean) & $59.5 \pm 10.84$ & $56.3 \pm 13.2$ & .200 \\
\hline Male sex & $28(87.5)$ & $32(94.2)$ & .400 \\
\hline Hypertension & $16(55)$ & $13(39.4)$ & .390 \\
\hline Diabetes mellitus & $7(21.9)$ & $10(30.3)$ & 440 \\
\hline Dyslipidemia & $4(12.5)$ & $0(0)$ & .053 \\
\hline Current smoking & $19(56.3)$ & $21(63.6)$ & .724 \\
\hline Prior ischemic events & $8(25)$ & $6(18.2)$ & .504 \\
\hline $\begin{array}{l}\text { Atherosclerotic ICA } \\
\text { occlusion }\end{array}$ & 23 (71.9) & $20(60.6)$ & .337 \\
\hline $\begin{array}{l}\text { Dissection/embolic ICA } \\
\text { occlusion }\end{array}$ & $9(18.8)$ & $13(39.4)$ & \\
\hline Territorial (MCA) infarct & $7(21.9)$ & $17(51.5)$ & .002 \\
\hline Hemodynamic infarct & $10(31.2)$ & $13(39.4)$ & \\
\hline Others small infarcts & $15(46.9)$ & $3(9.1)$ & \\
\hline ASPECTS $\geq 8$ & $28(87.5)$ & $14(42.4)$ & $<.001$ \\
\hline Median NIHSS (IQR) & $0.5(0-4)$ & 15 (17-19) & \\
\hline NIHSS $<5$ & $15(46.9)$ & $1(3.1)$ & $<.001$ \\
\hline AcomA, poor flow & $15(46.9)$ & $16(48.5)$ & .897 \\
\hline AcomA, good flow & $17(53.1)$ & $17(51.5)$ & \\
\hline Ipsilateral PcomA, poor flow & $16(50)$ & $23(69.7)$ & .105 \\
\hline Ipsilateral PcomA, good flow & $16(50)$ & $10(30.3)$ & \\
\hline $\begin{array}{l}\text { Contralateral PcomA, poor } \\
\text { flow }\end{array}$ & $21(65.6)$ & $22(66.7)$ & .929 \\
\hline $\begin{array}{l}\text { Contralateral PcomA, good } \\
\text { flow }\end{array}$ & $11(34.4)$ & $11(33.3)$ & \\
\hline Ipsilateral OA, absent & $8(25)$ & $18(54.5)$ & .015 \\
\hline Ipsilateral OA, present & $24(75)$ & $15(45.5)$ & \\
\hline Contralateral OA, absent & $3(9.4)$ & $4(12.1)$ & 1.000 \\
\hline Contralateral OA, present & $29(90.6)$ & $29(87.9)$ & \\
\hline LC, poor flow & $3(9.4)$ & $15(45.5)$ & .001 \\
\hline LC, good flow & $29(90.6)$ & $18(54.5)$ & \\
\hline No. of collaterals, $\geq 2$ & $27(84.4)$ & $17(51.5)$ & .005 \\
\hline
\end{tabular}

Note:-IQR indicates interquartile range.

${ }^{a}$ Data are number and percentage unless otherwise indicated.

Table 2: Multiple logistic regression analyses for predictors of poor 3-month outcome

\begin{tabular}{lccc}
\hline \multicolumn{1}{c}{ Variables } & OR & 95\% Cl & $P$ Value \\
\hline Model 1 $^{\mathrm{a}}$ & & & \\
$\quad$ Poor LC flow & 0.28 & $0.07-1.19$ & .085 \\
$\quad \begin{array}{l}\text { Absent ipsilateral OA } \\
\text { NIHSS } \geq 5\end{array}$ & 0.45 & $0.13-1.54$ & .201 \\
$\begin{array}{l}\text { Model 2 } \\
\quad \text { Absent ipsilateral OA or poor } \\
\quad \text { LC flow }\end{array}$ & 16.44 & $1.90-142.18$ & .011 \\
$\quad$ NIHSS $\geq 5$ & 19.21 & $1.35-14.93$ & .014 \\
\hline
\end{tabular}

${ }^{a}$ In model 1 of multiple logistic regression analysis, the ipsilateral OA and LC were independently analyzed along with the NIHSS.

${ }^{b}$ In model 2, both the ipsilateral OA and LC were analyzed together (presence of both secondary collaterals vs absence of either of them or both) along with the NIHSS for predicting 3-month outcome.

eral OA was a significant predictor of poor outcome at 3 months in patients with symptomatic cervical ICA occlusion.

The presence of reversed OA flow is considered a harbinger of poor cerebral hemodynamics in patients with carotid occlusion, but data regarding its effect on outcome were inconclusive. ${ }^{10}$ Tsai et $\mathrm{al},{ }^{4}$ in a retrospective study of patients with severe ICA stenosis or occlusion with transcranial Doppler and MRA, showed that the patients with ICA occlusion had a significantly higher incidence of reversed OA flow compared with patients with unilateral high- 


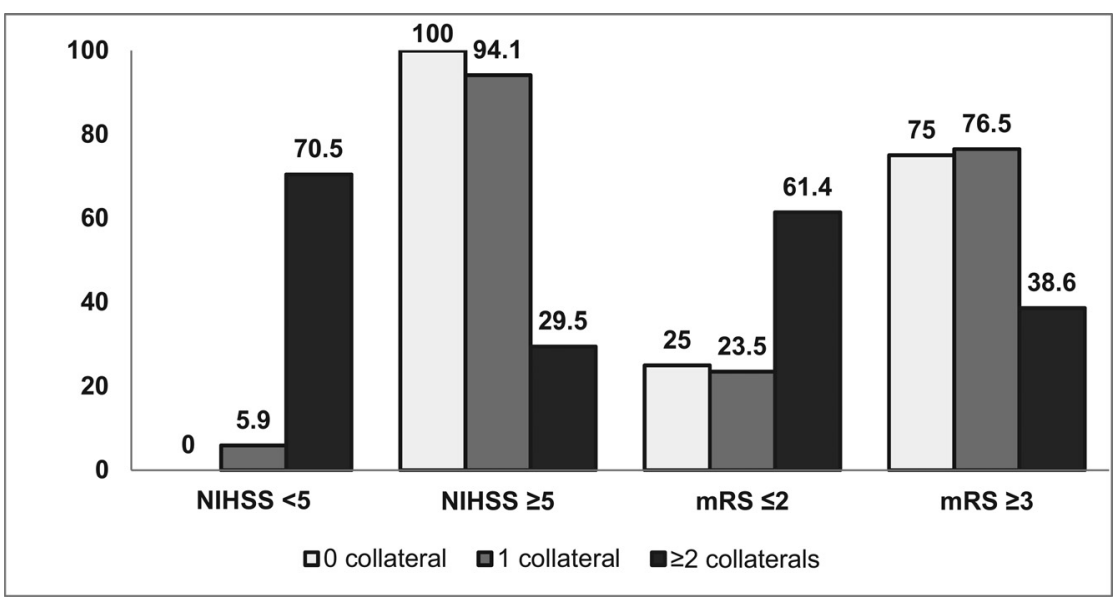

FIG 5. Number of collaterals with initial stroke severity and 3-month outcome. atresia of vessels or a fetal posterior cerebral artery, which might reduce their role as a collateral route. ${ }^{22,23}$ Alternatively, their role as a reliable alternative conduit may be questionable. Some patients with severe stroke or mortality due to malignant MCA stroke might not have reached our hospital, and their collateral status, including the communicating arteries, was unknown. More likely, such patients might have had poor collaterals and poor hemodynamic compensation through the communicating arteries, which could have resulted in greater stroke severity.

Our study patients were a homogeneous cohort because we excluded patients with intracranial ICA occlusion and tandem MCA occlusion and those who grade carotid stenosis. Reversed OA flow was considered a marker of impaired cerebral hemodynamics in patients with severe carotid disease because it was associated with poor functional outcome. On the contrary, stroke outcome improved by $10 \%-20 \%$ in the reversed OA flow group compared with the forward OA flow group in subjects with severe intracranial carotid stenosis $(\geq 50 \%) .{ }^{11}$ This finding is in accord with our study, which showed that most patients with absent ipsilateral OA compared with its presence were associated with poor outcome $(69.2 \%$ versus $38.5 \%$; $P=.02$ ). Although the role of the OA as an effective collateral is questionable, owing to its small caliber, the retrograde flow through the OA might compensate for the insufficiency in the anterior portion of Willisian circulation, and its presence may indicate an overall good collateral perfusion. ${ }^{12-14}$

Previous studies have suggested an important role for LC in determining the extent of infarct, outcome, and response to revascularization therapy in acute stroke. ${ }^{5,7,15-17}$ Similarly, our study showed that 15 of 18 patients with poor flow through the LC had poor outcome, and all of them had moderate-to-severe stroke at onset. The diversion of blood flow through the leptomeningeal vessels provides sufficient oxygenation to the ischemic bed distal to the occlusion. Not only the quantity of collaterals but also the quality of oxygenation through the slow flow along leptomeningeal vessels determines the fate of the ischemic bed. ${ }^{2,18}$

In our study, patients with $\geq 2$ collaterals (ipsilateral OA, ipsilateral PcomA, AcomA, and LC) had excellent outcome, indicating that as more collaterals are recruited, more blood flow is diverted to the ischemic areas, providing an effective compensatory mechanism (Fig 5). A similar finding was observed in ICA dissection in which patients with $<2$ collaterals showed a significant increased risk of poor recovery. ${ }^{19}$ The annual risk of recurrent ischemic events was also reduced in patients when more collaterals were recruited. ${ }^{6}$ Hence the presence of $>1$ major collateral pathway supplying the hemisphere on the side of the occlusion had a positive association with better outcome.

Willisian collateral flow was considered an immediate diverter of blood flow in the event of any large-vessel occlusion. ${ }^{2,20,21}$ However, in this study, the flow through the AcomA and PcomA was not independently predictive of stroke severity or outcome. This may be due to the anatomic variations such as hypoplasia or underwent revascularization therapy. The key advantage of our study was the uniformity in the study protocol, with a single imaging technique (CTA) for the concurrent assessment of both the primary and secondary collaterals. The images were independently read by an interventional neuroradiologist and a stroke neurologist with reasonable interrater agreement.

A major limitation of the study was the inability to assess the direction of flow in the OA by CTA. Multiphasic CTA was not performed in our patients, and how a vessel is filled (antegrade or retrograde) could not be determined. Although none of the techniques used to study cerebral collaterals have been systematically studied or validated, transcranial Doppler or DSA is generally preferred for the delineation of retrograde-versus-forward flow. ${ }^{18,22}$ We included patients up to 3 weeks after the event, which would have a bearing on the interpretation of the collateral status because time is a critical variable and collateral circulation is dynamic. ${ }^{18,24-26}$ The other limitation was the selection bias in which patients who had severe stroke or who died early are clearly not represented in our sample (not referred to our institution), and obviously they might have had poor collateral circulation, including absent flow through the AcomA and PcomA. Probably this would explain the role of communicating arteries being insignificant in this study. We also did not analyze the role of intracranial ICA stenosis and anomalies of the circle of Willis. A larger sample size could have helped us analyze the factors determining stroke severity, including the role of collaterals, which was another limitation.

\section{CONCLUSIONS} CTA is an important tool in predicting 3-month outcome in patients with symptomatic ICA occlusion. Secondary collaterals (leptomeningeal collaterals and ophthalmic artery) rather than Willisian flow might be more influential in determining the outcome in such patients.

\section{ACKNOWLEDGMENTS}

The authors acknowledge the contribution of Mr Babunath B., technical assistant (Department of Imaging Sciences and Interventional Radiology), for the processing of CTA images.
Our study shows that assessment of collateral circulation with 
Disclosures: Bejoy Thomas-UNRELATED: Grants/Grants Pending: GE Healthcare, Comments: project grant for MRI projects. * Money paid to the institution.

\section{REFERENCES}

1. Powers WJ. Cerebral hemodynamics in ischemic cerebrovascular disease. Ann Neurol 1991;29:231-40 CrossRef Medline

2. Liebeskind DS. Collateral circulation. Stroke 2003;34:2279-84 CrossRef Medline

3. Miteff F, Levi CR, Bateman GA, et al. The independent predictive utility of computed tomography angiographic collateral status in acute ischaemic stroke. Brain 2009;132:2231-38 CrossRef Medline

4. Tsai CL, Lee JT, Cheng CA, et al. Reversal of ophthalmic artery flow as a predictor of intracranial hemodynamic compromise: implication for prognosis of severe carotid stenosis. Eur J Neurol 2013;20: 564-70 CrossRef Medline

5. Liebeskind DS, Jahan R, Nogueira RG, et al; SWIFT investigators. Impact of collaterals on successful revascularization in Solitaire FR with the intention for thrombectomy. Stroke 2014;45:2036-40 CrossRef Medline

6. Vernieri F, Pasqualetti P, Matteis M, et al. Effect of collateral blood flow and cerebral vasomotor reactivity on the outcome of carotid artery occlusion. Stroke 2001;32:1552-58 CrossRef Medline

7. Lima FO, Furie KL, Silva GS, et al. The pattern of leptomeningeal collaterals on CT angiography is a strong predictor of long-term functional outcome in stroke patients with large vessel intracranial occlusion. Stroke 2010;41:2316-22 CrossRef Medline

8. Bang OY, Lee PH, Heo KG, et al. Specific DWI lesion patterns predict prognosis after acute ischaemic stroke within the MCA territory. J Neurol Neurosurg Psychiatry 2005;76:1222-28 CrossRef Medline

9. Maas MB, Lev MH, Ay H, et al. Collateral vessels on CT angiography predict outcome in acute ischemic stroke. Stroke 2009;40:3001-05 CrossRef Medline

10. Hofmeijer J, Klijn CJ, Kappelle LJ, et al. Collateral circulation via ophthalmic artery or leptomeningeal vessels is associated with impaired cerebral vasoreactivity in patients with symptomatic carotid artery occlusion. Cerebrovasc Dis 2002;14:22-26 CrossRef Medline

11. Sung YF, Tsai CL, Lee JT, et al. Reversal of ophthalmic artery flow and stroke outcomes in Asian patients with acute ischemic stroke and unilateral severe cervical carotid stenosis. PLoS One 2013;8: e80675 CrossRef Medline

12. Orge F, Harris A, Kagemann L, et al. The first technique for noninvasive measurements of volumetric ophthalmic artery blood flow in humans. Br J Ophthalmol 2002;86:1216-19 CrossRef Medline

13. Reinhard M, Muller T, Guschlbauer B, et al. Dynamic cerebral auto- regulation and collateral flow patterns in patients with severe carotid stenosis or occlusion. Ultrasound Med Biol 2003;29:1105-13 CrossRef Medline

14. Saqqur M, Demchuk AM, Hill MD, et al. Bedside emergency transcranial Doppler diagnosis of severe carotid disease using orbital window examination. J Neuroimaging 2005;15:138-43 CrossRef Medline

15. Bang OY, Saver JL, Kim SJ, et al; UCLA-Samsung stroke collaborators. Collateral flow averts hemorrhagic transformation after endovascular therapy for acute ischemic stroke. Stroke 2011;42:2235-39 CrossRef Medline

16. Bang OY, Saver JL, Buck BH, et al; UCLA collateral investigators. Impact of collateral flow on tissue fate in acute ischaemic stroke. J Neurol Neurosurg Psychiatry 2008;79:625-29 Medline

17. McVerry F, Liebeskind DS, Muir KW. Systematic review of methods for assessing leptomeningeal collateral flow. AJNR Am J Neuroradiol 2012;33:576-82 CrossRef Medline

18. Liebeskind DS. Collaterals in acute stroke: beyond the clot. Neuroimaging Clin N Am 2005;15:553-73, x CrossRef Medline

19. Silvestrini M, Altamura C, Cerqua R, et al. Early activation of intracranial collateral vessels influences the outcome of spontaneous internal carotid artery dissection. Stroke 2011;42:139-43 CrossRef Medline

20. Miralles M, Dolz JL, Cotillas J, et al. The role of the circle of Willis in carotid occlusion: assessment with phase contrast MR angiography and transcranial duplex. Eur J Vasc Endovasc Surg 1995;10:424-30 CrossRef Medline

21. Hartkamp MJ, van Der Grond J, van Everdingen KJ, et al. Circle of Willis collateral flow investigated by magnetic resonance angiography. Stroke 1999;30:2671-78 CrossRef Medline

22. Shuaib A, Butcher K, Mohammad AA, et al. Collateral blood vessels in acute ischaemic stroke: a potential therapeutic target. Lancet Neurol 2011;10:909-21 CrossRef Medline

23. Riggs HE, Rupps C. Variation in form of circle of Willis: the relation of the variations to collateral circulation-anatomical analysis. Arch Neurol 1963;8:8-14 CrossRef Medline

24. Widder B, Kleiser B, Krapf H. Course of cerebrovascular reactivity in patients with carotid artery occlusions. Stroke 1994;25:1963-67 CrossRef Medline

25. Derdeyn CP, Videen TO, Fritsch SM, et al. Compensatory mechanisms for chronic cerebral hypoperfusion in patients with carotid occlusion. Stroke 1999;30:1019-24 CrossRef Medline

26. Liebeskind DS, Sansing LH. Willisian collateralization. Neurology 2004;63:344 CrossRef Medline 